\title{
Characterization of clastic sedimentary enviroments by clustering algorithm and several statistical approaches - case study, Sava Depression in Northern Croatia
}

\author{
Janina Horváth \\ Department of Geology and Palaeontology \\ University of Szeged, Szeged
}

\author{
Tomislav Malvić \\ Sector for Geology and Engineering \\ INA-Oil Industry Plc. \\ Department for Geology and Geological Engineering, \\ Faculty of Mining, Geology and Petroleum \\ Engineering, University of Zagreb, Zagreb
}

\begin{abstract}
This study demonstrates a method to identify and characterize some facies of turbiditic depositional environments. The study area is a hydrocarbon field in the Sava Depression (Northern Croatia). Its Upper Miocene reservoirs have been proved to represent a lacustrine turbidite system. In the workflow, first an unsupervised neural network was applied as clustering method for two sandstone reservoirs. The elements of the input vectors were the basic petrophysical parameters. In the second step autocorrelation surfaces were used to reveal the hidden anisotropy of the grid. This anisotropy is supposed to identify the main continuity directions in the geometrical analyses of sandstone bodies. Finally, in the description of clusters several parametric and nonparametric statistics were used to characterize the identified facies. Obtained results correspond to the previously published interpretation of those reservoir facies.
\end{abstract}

Key words: unsupervised neural networks, clustering, nonparametric statistics, autocovariance, recognition of sub-environments, Upper Miocene, sandstones, Sava Depression

\section{Introduction}

The goal of this study is to demonstrate an approach for identification of depositional facies using the neural network tool as a clustering method. The components of the input vectors are porosity, water saturation and shale content, coming from quantitative well-log interpretations. This basic petrophysical data was used for interpreting the generated clusters by statistical approaches. Since the applied cluster algorithm can simultaneously handle several point data and

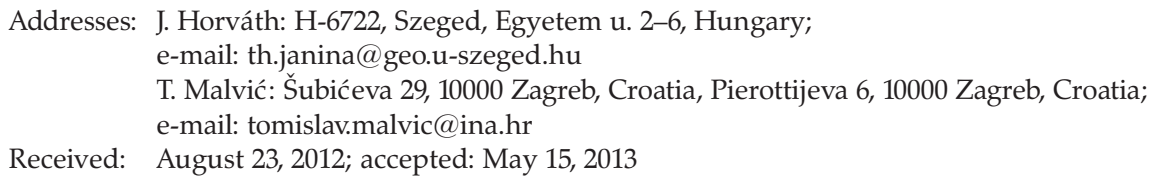


join more attributes (or properties) of data points, the formed clusters are characterized by complex underlying properties. These underlying structures were uncovered by exploratory data analyses and visualization approaches.

Different clustering methods and various neural network techniques are also frequently used to perform analysis on geologic data; this study also shows incorporation of a priori knowledge of a problem into the application of a neural network, i.e. the interpretation of depositional environments and mechanisms.

Since the clustering to segment the basic data set is not of equal classification type, this means that it is an unsupervised method, i.e. the data structure is explored in only one data set without a control set. This decides which type of neural network is applicable for the clustering in the study. Thus an unsupervised neural network, in this case the Kohonen network, was used. Despite the fact that the supervised network is more generally applied in several fields of geology, there are many examples for the application of unsupervised network as well. The unsupervised network is capable of solving specific problems, such as indirect data mining, that is, clustering, pattern recognition and visualization. The Kohonen network as a tool for identification has been demonstrated in several publications; in those cases the goals were lithofacies identification (Chang et al. 2002), a well-log interpretation for the determination of reservoir facies and fluid contents (Akinyokun et al. 2009) and classification of biogenic sedimentation (Ultsch et al. 1995).

This study also shows an application for the Kohonen network, with the aim of identifying depositional facies supplemented by statistical interpretation.

\section{Study area in Northern Croatia}

The study area is a hydrocarbon field which is situated in the western part of the Sava Depression, Northern Croatia, about $35 \mathrm{~km}$ to the east of Zagreb (Fig. 1), called the Sava Field. The clustering process was applied in two reservoirs of Upper Miocene age (Upper Pannonian). The entire sedimentary sequence of the field belongs to the Neogene and Quaternary. Generally, Middle and partially Upper Miocene sedimentation was highly influenced by the pre-Neogene basement paleorelief, which is of heterogeneous lithological composition (magmatic and metamorphic rocks).

The analyzed sequence is represented by Upper Miocene marl, siltstone and sandstone. The latter two clastic (psammitic) lithofacies were deposited by periodical turbidity currents in the entire depression (e.g. Šimon 1980; Novak Zelenika et al. 2012). Sedimentation was through cyclic turbidity flows in lacustrine environments during the Pannonian and Pontian, when the entire lacustrine area was constantly decreasing in size, depth and salinity (e.g. Vrbanac 1996; Malvić and Velić 2011). Sediment was reworked several times before its final deposition (Malvić et al. 2005; Malvić and Velić 2011). The sandstone bodies' morphology follow the direction of the turbidity currents: generally, in the central 


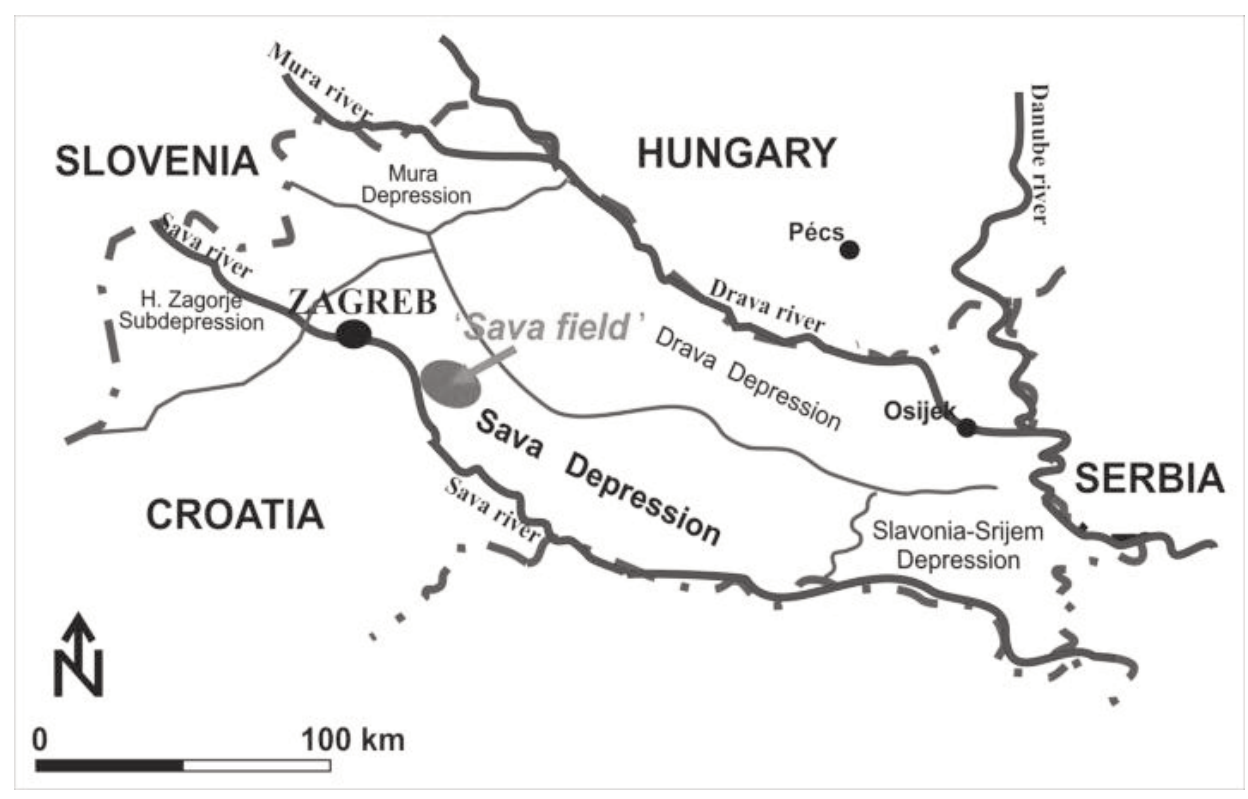

Fig. 1

Location of Study area, labeled as 'Sava' Field

part of the depression there appeared thick-bedded, fine-grained sandstone deposits, which are bounded at the margins by basin-plain marl (e.g., Saftic et al. 2003). A similar picture is proved for the lithofacies distribution in the entire depression, which implies that present-day reservoirs had originally been deposited in the deepest parts thereof.

\section{Methods}

Basic datasets

In this study the UNN clustering method was applied to two out of a total sequence of 11 reservoirs; this rock body reaches the total thickness between 120 and $150 \mathrm{~m}$. For both hydrocarbon reservoirs the data came from 79 wells; the inputs were the averages of the petrophysical parameters (porosity, water saturation, shale volume) and a categorical variable that describes the lithology using a code-number between 0 and 10, according to the shale content of the sandy deposit. For this study field the UNN classification processes have been presented in a previous publication (Horváth and Novak Zelenika 2011). Nevertheless that approach is here partially modified and extended, introducing small-scale analysis and repeated clustering process.

In the smaller-scale analysis the reservoirs were sliced by parallel surfaces to the base of the top-seal (Fig. 2). Between any two surfaces the interval thickness was 
Cut the reservoir rock body by parallel surfaces with the bottom of the sill

The vertical distance between any two surfaces was $5 \mathrm{~m}$
Fig. 2

Vertical decomposition of the rock body (based on the palinspastic principle)
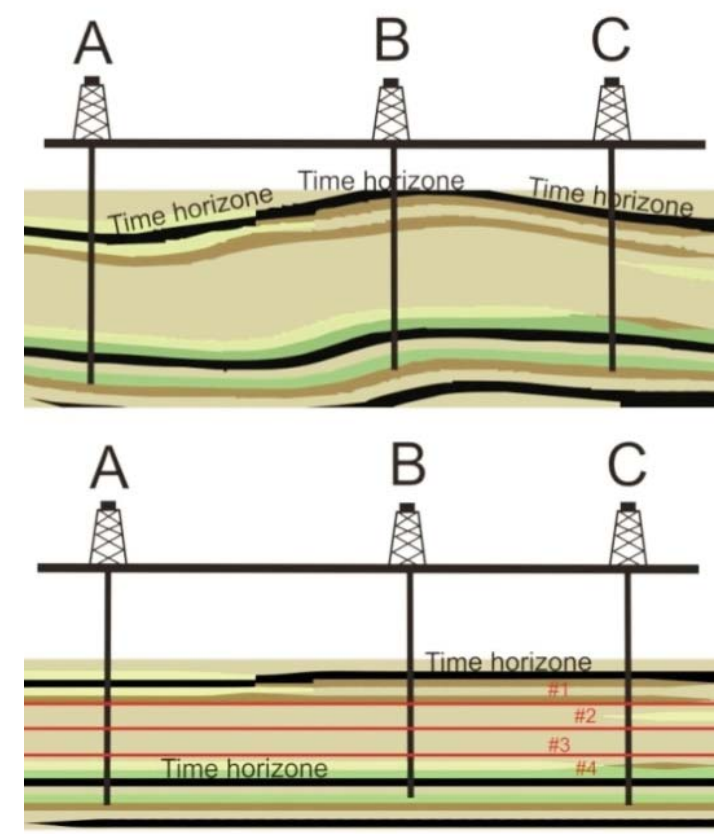

$5 \mathrm{~m}$ and for each separate level averages of the petrophysical values were calculated. Five meters below the top was acceptable since the average thickness of the reservoirs in the Ivanic Grad Formation (Upper Pannonian age) is 15-20 m. So, based on the shapes of E-logs, depths of 5, 10, 15, and sometimes $20 \mathrm{~m}$ below the top can be set as 'datum planes' for mapping. This small-scale heterogeneity analysis was introduced and described by Sebők-Szilágyi and Geiger (2012). The assigned average values to data locations on the slicing surfaces were the inputs for the repeated clustering process.

\section{Self-organized clustering method by neural network}

The clustering processes were the 'Self-organized map' (SOM), introduced by Kohonen $(1982,2001)$, an unsupervised neural network (UNN) and competitive process. The competitive and unsupervised learning algorithm implies that the network must have the ability to recognize the structure of the multidimensional basic data set, using the method of dimension reduction (Kohonen 1982; Haykin 1994; Patterson 1996; Fausett 1994). Usually the Kohonen network is labeled as a Self-Organized-Map process. This name $(\mathrm{SOM})$ shows that the neurons are arranged in a grid as a 'map' which is the Kohonen layer. The structure of the 
applied neural network and the Kohonen layer are presented in Fig. 3. The number of neurons are defined by the number of clusters and the neurons on the organized map are able to retain the relationship between the inputs through the lateral connection. Each neuron computes its weighted input (this is a linear process) and the neuron with the largest output is the 'winner'. In the next step of the learning processes only the weight of the winner neuron and its neighbors are changed. The weights of neighbor neurons are controlled by the lateral connection, which is a non-linear one.

The learning process of the data structure is carried out in an iterative manner using the modified Hebb Rule as the winning neuron algorithm (Lampinen et al. 2005).

The modified Hebb Rule is:

$w(t+1)=w(t)^{*} \eta(t)^{*}(x-w(t))$

where:

$x \quad-$ is the training case,

$w(t)$ - is weight,

$\eta(t) \quad$ - is the learning rate.

Contrary to the traditional clustering process, the presented method, using the Kohonen network for clustering, is able to recognize clusters in those situations where traditional cluster techniques fail to find any reasonable groups. Ultsch (1995) showed a geometrical example for this state.

\section{Spatial display of clusters}

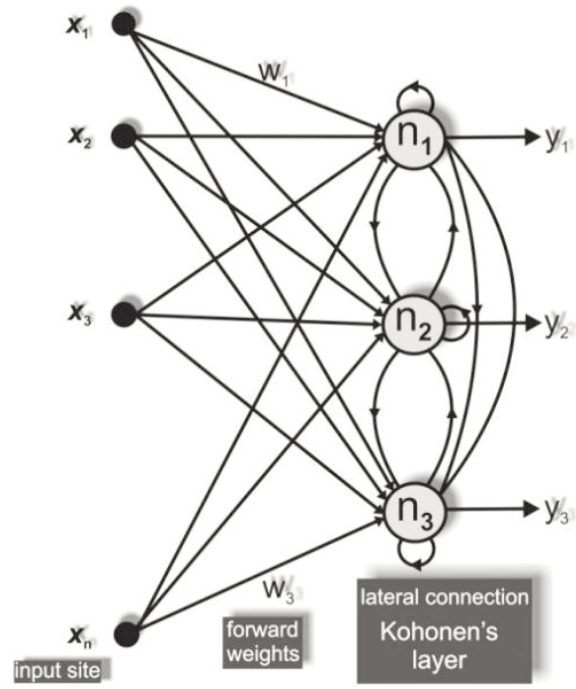

Fig. 3

Structure of Kohonen's neural network from Figure 6. One possible visualization of clusters (lithofacies) in lower (left) and upper (right) reservoir. The datum plane is $5 \mathrm{~m}$ below top of reservoirs

Using UNN, the process obtained a

classified point set, where the number of points equals the number of wells. For each point the variables represents a kind of code of the cluster type. Since any kind of classical gridding algorithm supposes the input variable to be continuous, in this case the classified points would be only point configurations on the map. The contours of the classified points cannot be drawn clearly if the interpretation is based on any grid of a code system. This statement is definitely true even for those gridding systems that do not use any interpolation, such as Voronoy polygons or the natural neighbors method.

Nevertheless, in Section 4 on the result maps one possible visualization of clusters is given, which is based on grid autocovariance of the petrophysical 
parameters. The grid autocovariance expresses the spatial patterns shown by the grid. This means that the autocovariance surface belongs to the grid and not to the basic data set; however, it was applied to use same anisotropies in the display of borders of clusters. The underlying anisotropies of petrophysical parameters as an advanced option supported the visualization of the spatial shape of clusters in the mapping process, using the natural neighbor gridding method. The spatial structures give a measure of the anisotropy of the grid through the orientation and the ratio of axes (anisotropy ratio). The variable used to determine the characteristics of the anisotropy was selected based on the largest weight in determining of clusters in the UNN process. For the case when correlation values were 0.5 , the axes represent the separation distances; the rate of axis and supplementary axes give a value of anisotropy in the presented surface of autocovariance. In this way the displayed clusters as a point configuration represent only one possible shape of depositional facies.

Presumably, using indicator kriging would be the most applicable solution, since this technique is designed to express those probabilities which would belong to the lateral distribution of the different clusters.

\section{Statistical analysis of clusters}

In the clustering processes the input variables represent the averages of the vertical data series from the reservoir, and in smaller-scale analysis from each $5 \mathrm{~m}$ interval. This means that each cluster was described by its averages value of input variables, but in this case the question is whether the statistics used to describe the clusters are significant. On the other hand, the sizes of formed clusters are different, and contain different amounts of elements. This fact made it difficult to compare the clusters, and in the case of a small number of set elements, the comparison is not suitable for nonparametric statistics.

In order to resolve the problem of statistical comparison of the clusters, Monte Carlo simulation was used. Through repetitive sampling Monte Carlo simulation increased the data number and resolution of the corresponding probability distribution. The simulations retained the characteristic group distributions and properties.

In each cluster the increased dataset reached 1500 elements. The improved datasets were compared to the measured log-values sets. The Goodman and Kruskal gamma coefficient was used to compare the datasets. These are the nonparametric statistics used for describing the relationship between two rankordered variables and show the probability of the difference between variables from the two datasets (Hill and Lewicki 2005). So the null hypothesis was that the samples of averages and measured samples are different.

The outcome of the test shows that the samples are significantly similar when the probability level of signification was 0.05 . Consequently the sets of averages 
were suitable to describe the clusters. The subsequent data analyses and comparison of clusters were based on this extended data set.

In the comparison of clusters the Mann-Whitney and Wilcoxon tests were used. Both tests are nonparametric alternative to the $t$-test, i.e. they do not require any assumption concerning the underlying distributions. These tests are the most powerful (or sensitive) nonparametric tests for comparing two independent populations. Hill and Lewicki (2005) mentioned in their work that in some instances the Mann-Whitney test may offer even greater power to reject the null hypothesis than the t-test, as well as that the Wilcoxon is also more powerful than the t-test.

Usually the Mann-Whitney test is applicable in the case of two independent samples and the Wilcoxon is useful for dependent ones. In comparing of the samples independence is presumed since the individual samples are not derived from each other. Each is measured or registered. It is assumed, however, that the clusters by UNN can be arranged in a hierarchical system. This hierarchy derives from depositional genetics. According to this the clusters close in the hierarchy are considered as dependent clusters and the more separate ones as independent clusters in the comparison. In order to determine which clusters are dependent and independent, their hierarchical relation was outlined through a summary table of clusters.

Thus the Mann-Whitney test checked the difference between the variables in the case of independent clusters and the Wilcoxon assay tested it in the case of dependent clusters.

\section{Results}

The UNN process created four clusters as sub-environments of a deep-water turbidite system. Table 1 shows the average correlation among the clusters (lithofacies) from different sub-environments. According to the weights of neural computation in the visualization of the result clusters, the porosity property was accentuated to describe the anisotropy. Under 0.5 correlation values the anisotropy ratio was 0.75 and the angle $40^{\circ}$ in the case of the lower reservoir; in the case of the upper reservoir the measured ratio was 0.6 and the angle was $45^{\circ}$. Under these anisotropy conditions, the contour of clusters was displayed by the mapping process (Fig. 4). Such a high anisotropic ratio outlined the paleodirections of transport, which are similar to that of an adjacent field (Novak Zelenika and Malvić 2011). Interestingly the paleo-transports can be still reconstructed today, although transtensional tectonics uplifted former depositional environments, where the reservoir deposits originally accumulated, into present-day anticlines. It is also easy to recognize the contours of the narrow main channel where the most of the sandy material carried by turbidites had been deposited.

Based on the shape of clusters and their averages properties, two principal groups were recognized. The $\mathrm{C} 1$ cluster is defined as massive marl sediments 
Table 1

Summary table of clusters (lithofacies) and identified sub-environments

\begin{tabular}{|c|c|c|c|c|c|c|c|}
\hline \multirow{5}{*}{ 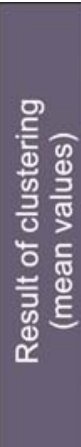 } & $\begin{array}{c}\text { Water } \\
\text { saturation } \\
(\%)\end{array}$ & $\begin{array}{c}\text { Shale } \\
\text { volume } \\
(\%)\end{array}$ & Porosity & Cluster & Sub-environments & 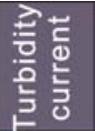 & Lithofacies \\
\hline & 98.88 & 94.04 & 1.41 & C1 & $\begin{array}{c}\text { normal basin pelitic } \\
\text { sediments }\end{array}$ & basin & massive marl \\
\hline & 71.02 & 55.45 & 13.84 & $\mathrm{C} 2$ & $\begin{array}{l}\text { turbidity channel } \\
\text { margins }\end{array}$ & \multirow{3}{*}{ 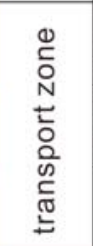 } & $\begin{array}{l}\text { laminated sandstone, } \\
\text { siltstones \& marls }\end{array}$ \\
\hline & 59.34 & 34.55 & 18.16 & C3 & $\begin{array}{l}\text { overbank deposits } \\
\text { along the channels }\end{array}$ & & $\begin{array}{l}\text { thin sandstones and } \\
\text { interrupted siltstones }\end{array}$ \\
\hline & 52.08 & 32.13 & 21.30 & $\mathrm{C} 4$ & $\begin{array}{l}\text { central part } \\
\text { of channel }\end{array}$ & & $\begin{array}{c}\text { massive } \\
\text { sandstones }\end{array}$ \\
\hline
\end{tabular}

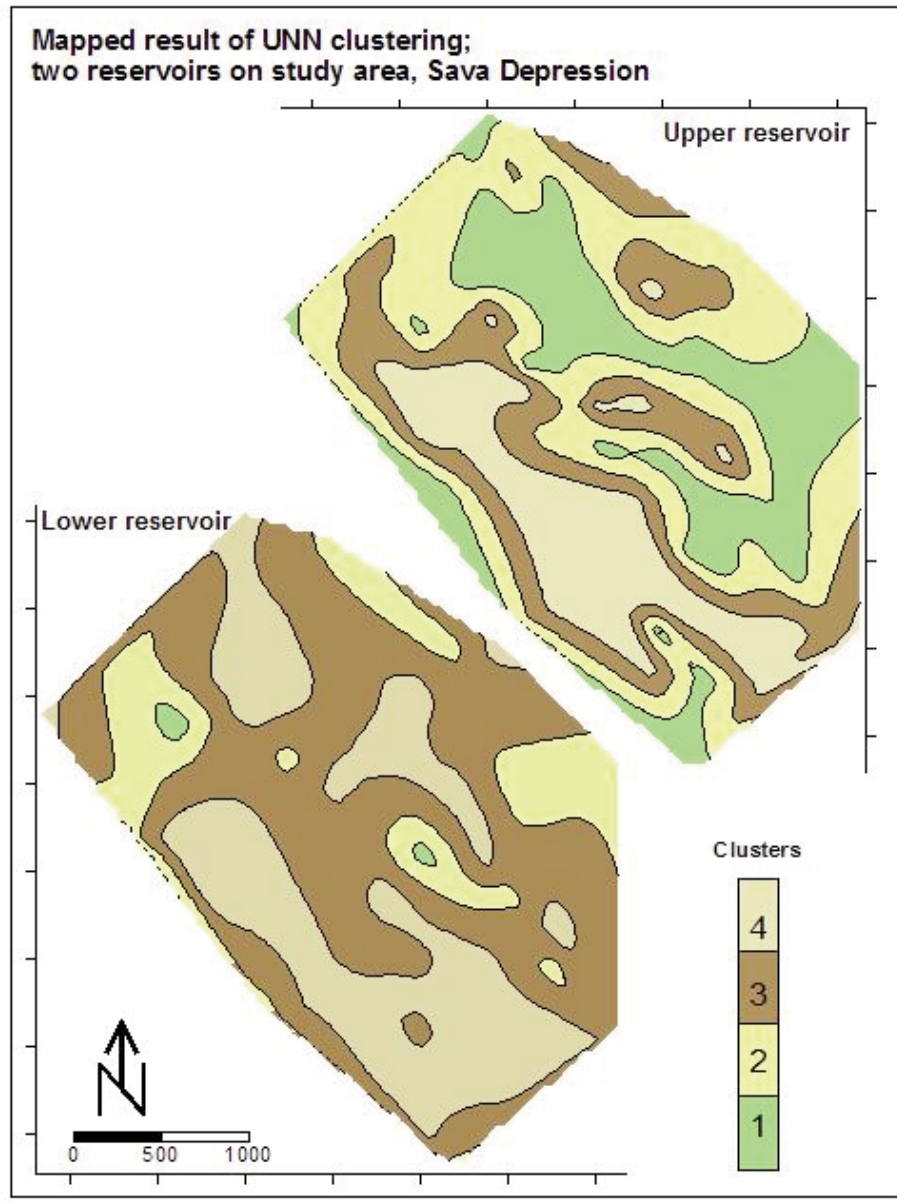

Fig. 4

One possible visualization of clusters (lithofacies) distribution 
with very low effective porosity, and dominantly pelitic grain size. It was continuously deposited by normal lacustrine basin pelitic sedimentation in the Sava Depression during the Upper Miocene.

The other group includes the $\mathrm{C} 2-\mathrm{C} 3-\mathrm{C} 4$ clusters directly deposited by the turbiditic currents. The results table also shows that these two main groups are arranged in a depositional genetic hierarchy, where the group consisting of $\mathrm{C} 1$ is located at a greater distance from the other. Therefore this cluster was compared to the others with Wilcoxon test, where the null hypothesis was that the ranks of medians are equal. According to the test the $\mathrm{C} 1$ cluster is significantly separated from the others; these clusters correspond to three sub-environments. Each is characterized by its own averages values of porosity, thickness and sand/shale ratio. Thus the visualized contour of the $\mathrm{C} 4$ cluster represents the part of the channel geometry linked to higher porosity values, and so to the coarsest sediment deposited into the deepest parts of the depression. The C3 means represent overbank deposits along the central part or transitional zone. These C3 and $\mathrm{C} 4$ clusters, observed together, show the main sediment transport direction (NW-SE) of the densest part of turbiditic current. Finally C2, as the set of the smallest psammitic and partially pelitic sediment (i.e. silt-size particles), represents the final range of the finest turbiditic fraction deposition. Those clusters generally correspond to Bouma facies Td-Te.

The described clusters correspond perfectly to lithofacies which are defined as typical for Upper Miocene sedimentation in the Sava Depression (Vrbanac et al. 2010). It was possible to establish a correlation between thick-layered massive sandstones (F1) and cluster C4. The facies of thin sandstone layers and interrupted siltstone (F2) corresponds to $\mathrm{C} 3$ and that of laminated sandstone, siltstone and marl (F3) to cluster C2. Finally the facies of massive marl (F4) is cluster $\mathrm{C} 1$. The results are in accordance with the previously published models of the depositional history in the Sava Depression (e.g. Šimon 1980; Vrbanac 1996; Malvić and Velić 2011).

According to the exploration data analysis (Fig. 5) the clusters of the transit zone are different, especially for the porosity values. In the case of C3 and C4, however, the shale content and water saturation showed higher affinity in distribution. This is an additional reason why the analysis was extended by comparison in a nonparametric statistical way. The C2, C3 and C4 clusters are dependent, due to relation connections in the depositional genetic hierarchy. Therefore the Mann-Whitney test was used to compare those clusters. The null hypothesis was that the ranks of medians are equal. In each variable case the probability of test was less than the threshold 0.05 value, so they are indeed statistically significant, different, separated clusters.

The displayed form of cluster is not able to show perfectly well the central transport region and margin toward the cluster of overbank deposit. The total thickness varies by a large interval, approx. 5-20 m. Therefore the concept was that the clusters (lithofacies) include sediments from several consecutive 

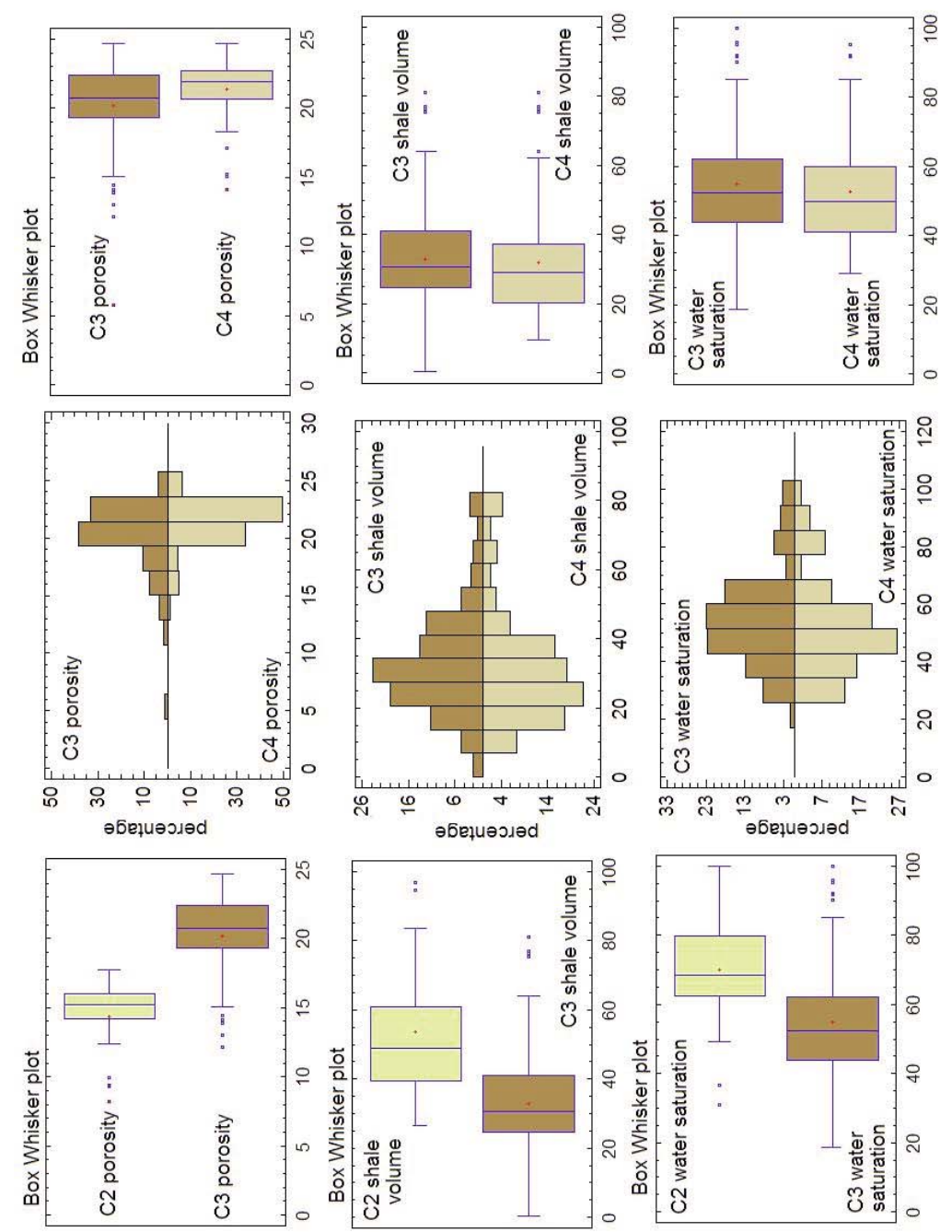

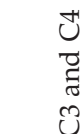
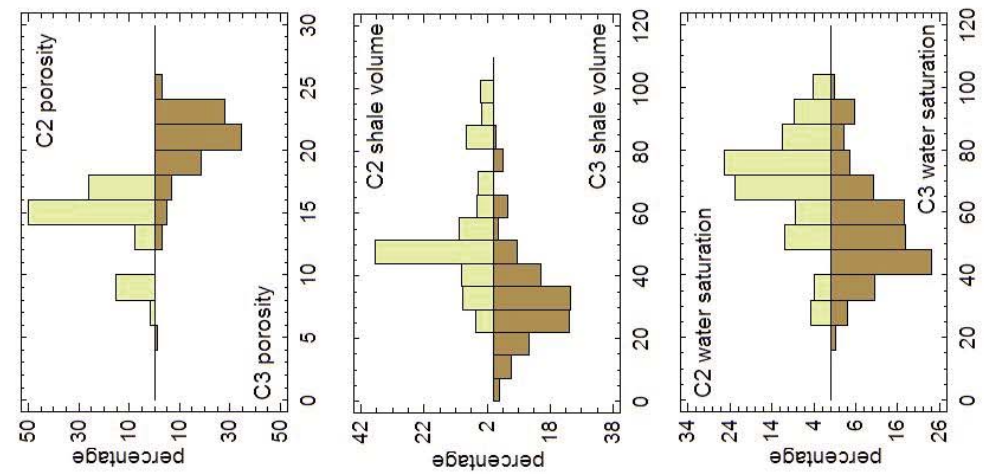

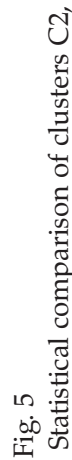

Central European Geology 56, 2013 
turbiditic events and the presented shape shows amalgamated deposits, sometimes with erosional contact at the base. Consequently, the sand content and net thickness values do not presently perfectly show paleo-directions of turbiditic flows, but a general trend was observed, especially after appropriate scaling was selected. It was especially valid for the $\mathrm{C} 4$ cluster where the net thickness reached the total thickness almost everywhere.

In the small-scale analysis the clustering process was repeated in same way with collective data input from each 5 m-thick horizon of the sliced rock body. In the UNN initial setting the cluster number was same. The UNN was run with four clusters. Table 2 shows the main results compared to those of the first and repeated clustering. According to the summary table the second clustering shows averages very close to those of the first process.

Considering the Change in the clusters after the second clustering process, it is observed that the $\mathrm{C} 2$ cluster has been modified the most. In those boreholes

Table 2

Summary table with comparison between the results of first clustering and repeated cluster process

\begin{tabular}{|c|c|c|c|c|c|c|c|c|c|c|}
\hline \multirow{5}{*}{ 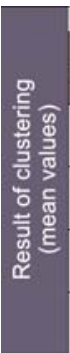 } & $\begin{array}{l}\text { In the sn } \\
\text { Water } \\
\text { saturation } \\
(\%)\end{array}$ & $\begin{array}{c}\text { tall scale } \\
\text { Shale } \\
\text { volume } \\
(\%)\end{array}$ & Porosity & Cluster & Lithofacies & $\begin{array}{c}\text { In the fi } \\
\text { Water } \\
\text { saturation } \\
(\%)\end{array}$ & $\begin{array}{c}\text { cluste } \\
\text { Shale } \\
\text { volume } \\
(\%)\end{array}$ & Porosity & Sub-environments & 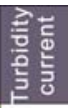 \\
\hline & 99.09 & 92.92 & 1.52 & C1 & massive marl & 98.88 & 94.04 & 1.41 & $\begin{array}{c}\text { normal basin pelitic } \\
\text { sediments }\end{array}$ & basin \\
\hline & 79.02 & 61.77 & 10.80 & $\mathrm{C} 2$ & $\begin{array}{l}\text { laminated sandstone, } \\
\text { siltstones \& marls }\end{array}$ & 71.02 & 55.45 & 13.84 & $\begin{array}{c}\text { turbidity channel } \\
\text { margins }\end{array}$ & \multirow{3}{*}{ 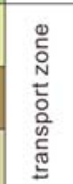 } \\
\hline & 56.87 & 38.48 & 18.82 & $\mathrm{C} 3$ & $\begin{array}{l}\text { thin sandstones and } \\
\text { interupted siltstones }\end{array}$ & 59.34 & 34.55 & 18.16 & $\begin{array}{l}\text { overbank deposits } \\
\text { along the channels }\end{array}$ & \\
\hline & 50.06 & 25.10 & 22.17 & $\mathrm{C} 4$ & $\begin{array}{l}\text { massive } \\
\text { sandstones }\end{array}$ & 52.08 & 32.13 & 21.30 & $\begin{array}{l}\text { central part } \\
\text { of channel }\end{array}$ & \\
\hline
\end{tabular}

where C2 and some case C3 clusters were identified using the averages of the entire vertical series, the sediment was subdivided into several different types of clusters, which indicates that the averaging provides only a relatively rough approach. The differences are traceable through the spatial pattern of clusters. Fig. 6 represents the highest $5 \mathrm{~m}$-thick horizon in both reservoirs.

As an example, Fig. 7 demonstrates the case where a cluster (f.i. C3) decomposes into several different types of clusters (from the smaller-scaling cluster process). This new process indicates that the $\mathrm{C} 3$ cluster contains a finingupward series. What this means is that in the first scaling, the clusters represent averages of the lithologic section while those of the second one are more detailed. The process also permits viewing subtle Changes such as fining or coarsening upward trends in sedimentary deposition.

This example showed relatively low resolution of clusters when compared with real lithological sections interpreted from e-logs (Fig. 7). However, using the "average" resolution of clustering it was possible the make a regional 3D cluster model, i.e. a 3D lithofacies distribution model (Fig. 8). 


\section{Spatial pattern of the clusters from the first $5 \mathrm{~m}$ thick horizon}
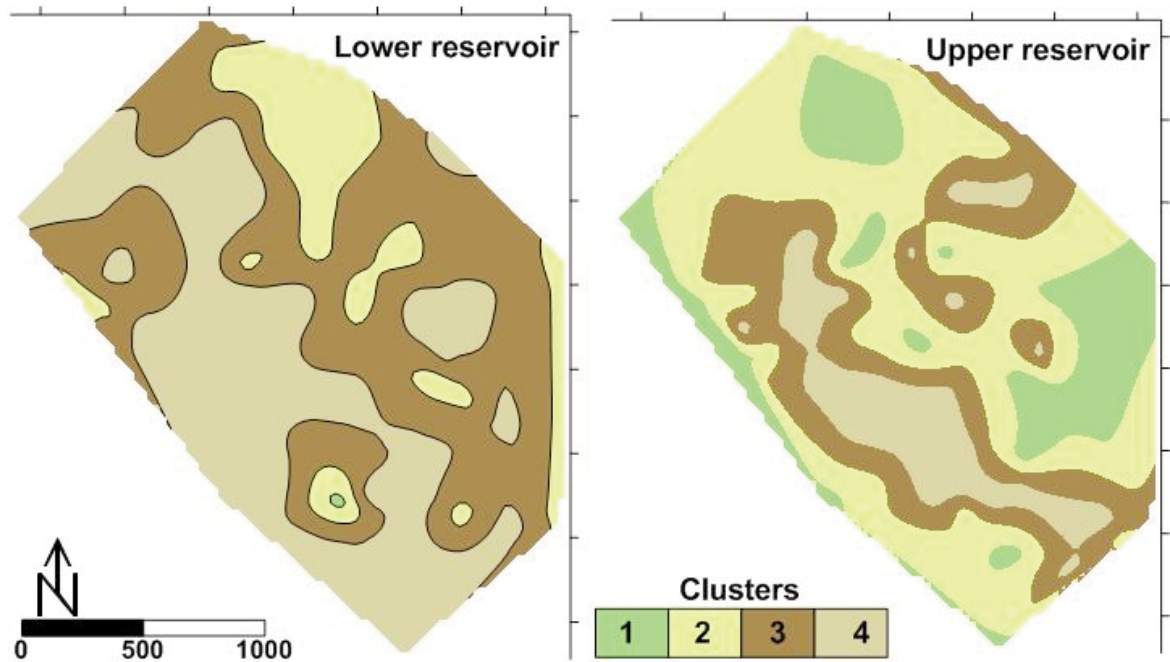

Fig. 6

One possible visualization of clusters (lithofacies) in lower (left) and upper (right) reservoir. The datum plane is $5 \mathrm{~m}$ below top of reservoirs

$\mathrm{SP}$

88880

$\circ$ ำ

لـ Depth (m)| Clusters Lithology

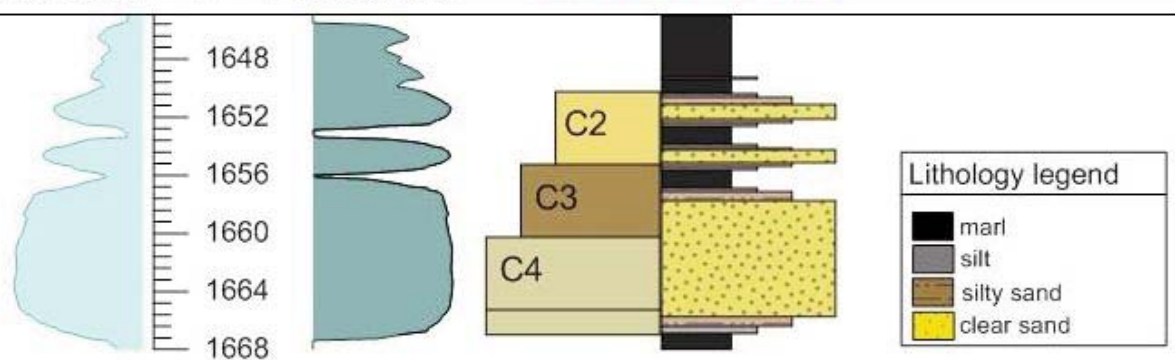

Fig. 7

E-logs, cluster and real lithology interpreted into part of Miocene sandstone reservoir, Sava Field 
It is clear that the analyzed study area represents an approximately $6 \mathrm{~km}$-long, NW to SE-oriented system of turbiditic deposits. The range of the channel system of the turbidite current based on the 3D model described the position of the channel-levee complex and, based on the 2D-mapped shape, display very well the feeder-channel position (i.e. the deepest depositional parts), mostly tectonically formed (by strike-slip faulting), within the paleo-depression. Figure 8 shows the lateral Change of lithofacies, which implies the movement of the main turbidite channel during the Upper Miocene.

In the lower reservoir the width of the feeder channel varies between 200 and $750 \mathrm{~m}$, while in the upper reservoir it is narrower, between 100 and $500 \mathrm{~m}$. According to the 3D model the width of the transit zone is 500 to $1200 \mathrm{~m}$ in the lower reservoir; in the other upper one it is considerably narrower, namely 200 to $700 \mathrm{~m}$. It appears to be a relatively narrow channel geometry, which corresponds to the above-defined high anisotropies as well. The two channel contours demonstrate the type of developing sedimentation and tectonically history: the sediment volume is reduced and the main channel axis is shifted toward the southeast and probably uplifted. This resulted in a smaller quantity of total turbiditic sediment being transported into this part of the Sava Depression.

According to three aspects of Mutti's classification of turbidite systems (Mutti 1979 and 1985) the analyzed turbiditic current in the Sava Field can be defined as an intermediate type between a middle and a small system in the distal part of Type-II (transition channel-lobes). It is similar to Type-III (channel-levee complexes) and the facies is predominantly characterized by pelitic sediments at
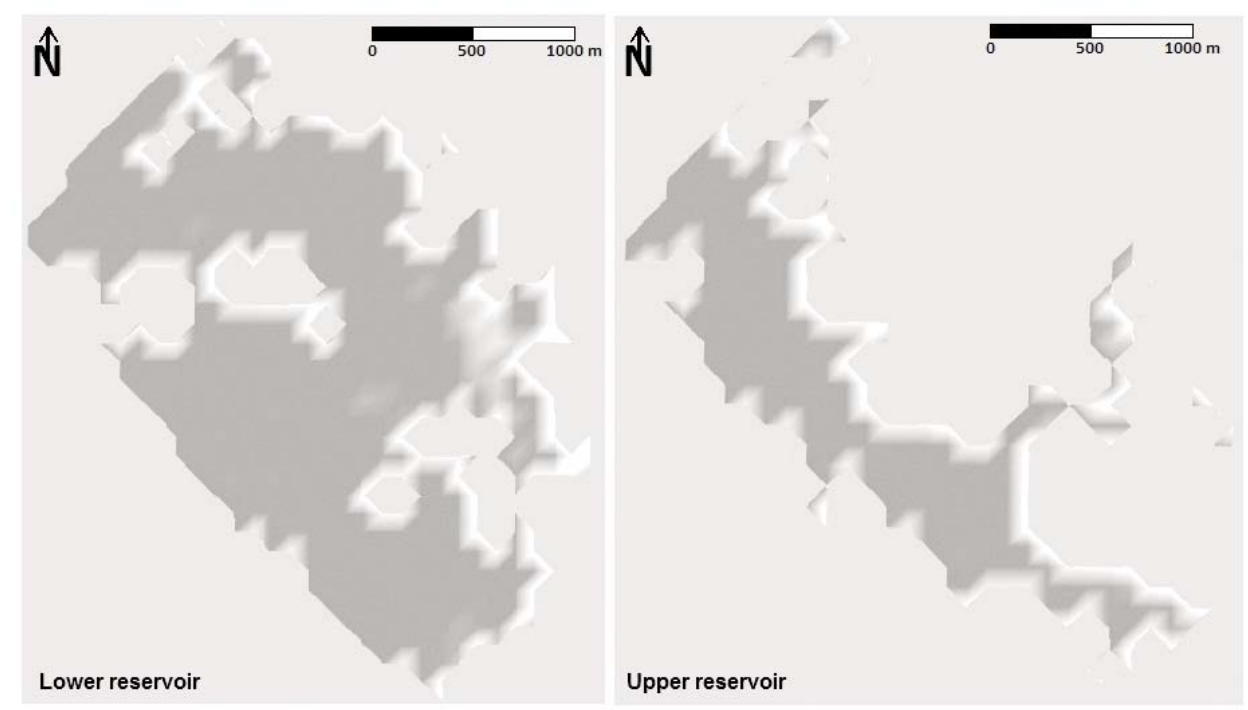

Fig. 8

Possible visualisation of clusters C3 and C4 (lithofacies) in lower (left) and upper (right) reservoir 
marginal a part of the transitional zone. The feeder-channel is filled by massive sandstone deposits, which are separated from channel-levee and overbank sediment.

In the lower reservoir the channel bifurcates but the branches do not separate completely from each other; rather they interweave or take on a lobe shape. This is possible if the channel-levee stability decreases (indeed, the marginal part of the transit zone has not been developed in this horizon) and/or the variability of the locus of the sandy channel deposit increases.

Since the sand/shale ratio is higher than $50 \%$ in general and higher than $60 \%$ in the central part of the transport zone, it belongs to the middle system. In addition to this feature, the extent of the system is usually several tens of kilometers (the facies can be followed and are known in other hydrocarbon fields in the Sava Depression) and the thickness of individual strata is between 1 and 5 $\mathrm{m}$; often they are amalgamated. What lies above the turbidity current can be recognized as the distal part of the retrograde medium turbidite systems.

\section{Conclusion}

The goal of this study is to present an approach for identification of depositional facies using the clustering method, which based on a kind of neural network application. In the case of the presented study area, the classified facies by SOM were identified as lithofacies that correspond perfectly to those defined as typical for Upper Miocene sedimentation in the Sava Depression (Vrbanac et al. 2010).

Traditional techniques of lithofacies identification are based partly on core data and partly on some key well-logs (e.g. gamma ray SP, etc.). Since there are never enough data from conventional core recovery, these identifications rely mostly on well-log interpretations. In this process one should simultaneously evaluate the different logs to obtain acceptable systems of lithofacies. This means the interpretation of a corrected e-log trend, usually using at least two types of e-log. The analyses of vertical profiles of well-logs are not the only specific tool for lithological descriptions, but are useful in subsurface facies analysis as well as sedimentological and stratigraphic interpretation (Pirson 1970; Serra 1985). The gamma and SP log vertical profiles are in close correlation with grain size tendency and the vertical evolution of some petrophysical parameters (such as porosity or sand content). However, certain phenomena like autochthonous radioactive minerals or pebbles in clay matrix can significantly modify these correlations.

In research the selected method is also able to handle more e-log data. It is based on three types of interpreted well-logs (porosity, shale, sand content and water saturation). The study revealed that reasonable and realistic lithological classification can be achieved by the applied parameters as well. This is important because porosity is highly dependent on digenesis. But here it turned out that the sediments were able to retain more strongly the depositional characteristics. 
According to the application, water saturation is also a kind of textural characteristic of sediments. This is possible since the hypothesis tests showed significant differences between the clusters, and the results can be interpreted in a sedimentological way.

In the practice of facies analysis it is generally the strategy to use any kind of clustering method, which is also based on the simultaneous application of several parameters, such as hierarchical cluster analyses or the K-means algorithm. The advantage of the SOM algorithm applied in this study is that it is more robust for the outliers than any traditional cluster algorithm. However, since SOM does not show any hierarchy of the sample groups, the decision of how many groups should be defined, and how to interpret the results, is definitely not straightforward. Other advantages of SOM are that this method is able to recognize clusters in those situations where k-means clustering techniques fail to find any reasonable groups, and that it allows the network to find its own solution, making it more efficient in association with inputs to develop the clusters in this fashion.

The analyses demonstrated that the UNN can segregate different clastic lithofacies deposited in different sub-environments of lacustrine turbiditic flows. The presented result is a complete model which is applicable to the processing of new information from further research in the elements of the obtained system.

\section{Acknowledgements}

This work is part of research performed as part of the project "Geomathematical methods for supporting or increasing hydrocarbon production in clastic reservoirs of the Pannonian Basin", supported by the Fund for Development of the University of Zagreb in 2012.

The authors would like to express their acknowledgement to the Sector for Geology and Reservoir Management of the Croatian Oil and Gas Company (INA Plc.) for permission to use data in this research. Also, many thanks to reviewers and to colleagues for their valuable suggestions and comments.

\section{References}

Akinyokun, O.C., P.A. Enikanselu, A.B. Adeyemo, A. Adesida 2009: Well Log interpretation model for the determination of lithology and fluid contents. - The Pacific Journal of Science and Technology, Springer.

Chang, H.C., D.C. Kopaska-Merkel, H.C. Chen 2002: Identification of lithofacies using Kohonen selforganizing maps. - Computers and Geosciences, 28., pp 223-229.

Fausett, L. 1994: Fundamentals of Neural Networks. - Architectures, Algorithms and Applications, Prentice Hall, Englewood Cliffs, NJ.

Haykin, S. 1994: Neural Networks: a Comprehensive Foundation. - The Knowledge Engineering Review, 13/4, pp. 409-412. New York.

Hill, T., P. Lewicki 2005: Statistics: Methods and Applications: A Comprehensive Reference for Science, Industry, and Data Mining. - StatSoft, Inc.; 1st edition; pp. 800. 
Horváth, J., K. Novak Zelenika 2011: Application of clustering methods for identification of palaeoenvironments, case study from Late Miocene sandstones, the Sava Depression. - Nafta, 62/11-12, pp. 365-376.

Kohonen, T. 1982: Self-organized formation of topologically correct feature maps. - Biological Cybernetics, 43, pp. 59-69.

Kohonen, T. 2001: Self Organized Maps. - Springer, Berlin.

Lampinen, T., M. Laurikkala, H. Koivisto, T. Honkanen 2005: Profiling Network Applications with Fuzzy C-means and Self-Organizing Maps. - Studies in Computational Intelligence "Classification and Clustering for Knowledge Discovery" 4, Springer, Berlin-Heidelberg.

Malvić, T., J. Velić, Z. Peh 2005: Qualitative-Quantitative Analyses of the Influence of Depth and Lithological Composition on Lower Pontian Sandstone Porosity in the Central Part of Bjelovar Sag (Croatia). - Geologia Croatica, 58/1, pp. 73-85.

Malvić, T., J. Velić 2011: Neogene Tectonics in Croatian Part of the Pannonian Basin and Reflectance in Hydrocarbon Accumulations. - In: Schattner, U. (Ed.): New Frontiers in Tectonic Research, At the Midst of Plate Convergence InTech, Rijeka, pp. 215-238.

Mutti, E. 1979: Turbidites et cones sours-margins profonds. - In: Homewood, P. (Ed.): Sedimentation Detritique (fluviatile, littorale et marine: Institut de Géologie, Université de Fribourg, Fribourg, Switzerland, pp. 353-419.

Mutti, E. 1985: Turbidite systems and their relations to depositional sequences. - In: Zuffa, G.G. (Ed.): Provenance of Arenites: NATO-ASI Series, D. Reidel Publishing Co., Amsterdam, pp. 65-93.

Novak Zelenika, K., J. Velić, T. Malvić 2012: Application of geostatistics in description of turbiditic depositional environments, case study Kloštar Field, Sava Depression. - In: Geiger, J., E. PálMolnár, T. Malvic (Eds): New horizons in central European geomathematics, geostatistics and geoinformatics, GeoLitera Publishing House, Szeged. pp. 61-72.

Novak Zelenika, K., T. Malvić 2011: Stochastic simulations of dependent geological variables in sandstone reservoirs of Neogene age: A case study of Kloštar Field, Sava Depression. Geologia Croatica, 64/2, pp. 173-183.

Patterson, D. 1996: Artificial Neural Networks. - Prentice Hall, Singapore: Prentice Hall, 477 p.

Pirson, S.J. 1970: Geologic well log analysis. - Houston, Gulf Publishing, 370 p.

Saftic, B., J. Velic, O. Sztanó, Gy. Juhász, Z. Ivkovic 2003: Tertiary subsurface facies, source rocks and hydrocarbon reservoirs in the SW part of the Pannonian basin (Northern Croatia and SouthWest Hungary). - Geologia Croatica, 56/1, pp. 101-122.

Šimon, J. 1980: Prilog stratigrafiji u taložnom sustavu pješèanih rezervoara Sava-grupe naslaga mlaðeg tercijara u Panonskom bazenu sjeverne Hrvatske (Contribution to stratigraphy of sandstone reservoirs depositional system in the Sava Group sediments in Late Tertiary of Pannonian Basin in the Northern Croati). - PhD dissertation, University of Zagreb, 66 p. (In Croatian.)

Sebők-Szilágyi, Sz., J. Geiger 2012: Sedimentological study of the Szőreg-1 reservoir (Algyő Field, Hungary): a combination of traditional and 3D sedimentological approaches. - Geologia Croatica, 65/1, pp. 77-90.

Serra, O. 1985: Sedimentary environments from wireline logs. - Houston, Schlumberger, 211 p.

Ultsch, A. 1995: Self Organizing Neural Networks perform different from statistical k-means clustering. - In Proc. GfKl, Basel, Swiss

Ultsch, A., D. Korus, A. Wehrmann 1995: Neural networks and their rules for classification in marine geology. - Raum und Zeit in Umweltinformations-systemen, 9th Intl. Symposium on Computer Science for Environmental Protection CSEP '95, Vol. I, ed. GI-Fachausschuß 4.6 "Informatik im Umweltschutz" vol. 7, Metropolis-Verlag, Marburg.

Vrbanac, B. 1996: Paleostrukturne isedimentološke analize gornjopanonskih naslaga formacije. Ivaniæ grad u savskoj depresiji. - PhD dissertation, Faculty of Natural Sciences, University of Zagreb, p. 121.

Vrbanac, B., J. Velić, T. Malvić 2010: Sedimentation of deep-water turbidites in the SW part of the Pannonian Basin. - Geologica Carpathica, 61/1, pp. 55-69. 